\title{
Palliation of malignant tracheobronchial obstruction by Nd-YAG laser: An update of experience at The Cleveland Clinic Foundation
}

\author{
DOUGLAS R. LIVINGSTON, D.O. \\ Wichita, Kansas \\ ATUL C. MEHTA, M.D., FCCP \\ JOSEPH A. GOLISH, M.D., FCCP \\ MUZAFFAR AHMAD, M.D., FCCP \\ GLENN DEBOER, M.D. \\ MARIAN Z. TOMASZEWSKI, M.D. \\ Cleveland, Ohio
}

\begin{abstract}
Photoresection of symptomatic, unresectable malignant tracheobronchial lesions using the neodymium-yttrium aluminum garnet (Nd-YAG) laser through a fiberoptic bronchoscope has previously been established as an accepted method of therapy. The present paper expands on the original study of this modality at the Cleveland Clinic Foundation and reports the results, complications, and caveats from 88 photoresection procedures performed at that institution between September 1983 and June 1986. Nd-YAG laser photoresection produced good to
\end{abstract}

excellent results in 69 of the 74 patients in the original and present studies; these data further support the procedure as a useful modality in the palliative treatment of malignant central airway obstruction. The procedure can be safely performed through the flexible as well as the rigid bronchoscope. Its role in prolonging survival and its synergism with standard chemotherapy and external beam radiation therapy, as well as with experimental methods such as photodynamic therapy and endobronchial radiation, remains to be determined.
In the past, treatment of unresectable malignant tracheobronchial obstruction was limited to radiation therapy, chemotherapy, and, on rare occasions, cryotherapy or biopsy resection. In recent years, laser technology has added a new dimension to the management of such lesions. Laser energy aimed at the obstructing lesion through an endoscopic system can produce dehydration, coagulation, carbonization, or even vaporization of the tumor tissue as desired. When necessary, coagulated tumor mass can be excised safely using endoscopic instruments. Thus, palliation of airway obstruction can be achieved in a closed fashion, without an incision or removal of functioning lung tissue.

Of the commonly used medical laser systems, carbon dioxide $\left(\mathrm{CO}_{2}\right)$ laser light has a wave length of $10,600 \mathrm{~nm}$., which prevents its passage through flexible quartz filament and requires either straight or mirrored articulated arms for its delivery; therefore, its role remains limited to easily reached structures, such as skin, open surgical wounds, larynx, or cervix. Argon (Ar) laser light has a shorter wave length of $516 \mathrm{~nm}$. and can be transmitted easily via flexible quartz filaments. However, it is not ideal for debulking because commercially available Ar laser units generate low power output and are unable to produce the immediate palliative effects that are so vital in many cases of airway obstruction.

Neodymium-yttrium aluminum garnet (Nd- 
YAG) laser light has a wave length of $1,050 \mathrm{~nm}$., and it can be easily transmitted through a flexible quartz filament. Using either a rigid or flexible bronchoscope, it can be aimed at lesions situated deep within the tracheobronchial tree. Nd-YAG laser light is invisible, is poorly absorbed by water as well as by hemoglobin, and has great tissue penetration. With available powerful laser units, efficient coagulation, carbonization, or vaporization of the tumor tissue can be produced by adjusting power output.

The thermal effect of Nd-YAG laser light was first introduced in the management of bleeding gastric lesions during $1977 .{ }^{1}$ Animal experimentation by Rutgeerts and associates ${ }^{2}$ demonstrated the efficiency and safety of Nd-YAG laser in alleviating gastrointestinal hemorrhage. This prompted investigation into its role in the management of lower respiratory tract lesions. Toty and coworkers, ${ }^{3}$ in 1981, and Dumon and associates, ${ }^{4}$ in 1982 , outlined the technique for Nd-YAG laser photoresection of endobronchial lesions; these investigators used a rigid bronchoscope for the majority of their patients. In 1983, McDougall and Cortese ${ }^{5}$ used the Nd-YAG laser with a fiberoptic bronchoscope successfully in the treatment of 20 patients with unresectable, malignant, symptomatic endobronchial lesions. Two other patients in their study had fatal massive hemorrhage from laser-induced damage to major vessels.

In the last few years, Nd-YAG laser photoresection has become a widely used therapy for the palliation of tracheobronchial obstruction resulting from unresectable benign or malignant lesions. ${ }^{3-7}$ In the initial study at The Cleveland Clinic Foundation, ${ }^{8} 39$ patients were treated for malignant tracheobronchial obstruction by Nd-YAG laser transmitted through a fiberoptic bronchoscope. The results confirmed the safety and efficacy of the modality. The present article collates our early and recent experience with Nd-YAG technology.

\section{Material and methods}

\section{Indications}

As established by history taking, physical examination, chest roentgenography, and fiberoptic bronchoscopy, indications for Nd-YAG laser photoresection included the presence of symptomatic, unresectable, exophytic, malignant endobronchial lesions involving the trachea or main bronchi. On occasion, even though lesions were arising from intermedius bronchus or lobar bronchi, they were selected for the therapy if they were large enough to obstruct a main bronchus or an adjacent lobe. Symptoms produced by these lesions included intractable cough, hemoptysis, dyspnea, asphyxiation, or those related to postobstructive pneumonitis, or partial or complete collapse of involved lung. Diagnosis of malignancy was established by endobronchial biopsy or review of pathology slides from previous procedures. All patients were considered to have unresectable disease, either because of the local or distal extent of the disease or cardiopulmonary limitations. Laser therapy was chosen only after conventional radiation or chemotherapy had failed unless the patient's life was thought to be in immediate danger. In those cases the therapy was performed prior to or during ongoing radiation or chemotherapy. Tumor cell type did not exclude the patients from undergoing photoresection.

\section{Laboratory studies}

Routine prelaser therapy work up included complete blood count, SMA-18 battery, determination of prothrombin time, activated partial thromboplastin time, arterial blood gas values, chest roentgenography, and screening spirometry before and after use of bronchodilators. Four units of typed and cross-matched whole blood were reserved for emergency use.

Whenever feasible and thought necessary, sector computed tomography (CT) scanning of the mediastinum utilizing contrast medium and/or magnetic resonance (MR) imaging of the chest were performed to study the relationship of the lesion to the major vascular structure of the thorax. These procedures revealed areas in which laser injury could lead to massive bleeding from perforation of the adjacent blood vessel. Complete pulmonary function testing (PFT) with and without bronchodilators was performed when possible. Pulmonary function impairment was gauged by several different modalities, depending upon chest $x$-ray findings, location of the lesion, and degree of airway obstruction. For example, flow-volume loop studies were utilized in patients with tracheal lesions, while quantitative ventilation and perfusion lung scanning assessed regional lung function in patients who had obstruction of the major bronchus with or wihout collapse of a lobe or whole lung. These studies, along with chest roentgenography and PFT, were repeated following laser therapy to determine the degree of improvement. Photographic documentation of the lesions and airway patency before and after therapy was obtained in each case.

\section{Anesthesia}

Patients were required to fast at least 8 hours prior to the induction of anesthesia. Premedications consisted of meperidine hydrochloride $(\mathrm{HCl})(0.5-1$ $\mathrm{mg} . / \mathrm{kg}$. of body weight), hydroxyzine $\mathrm{HCl}$ (25-50 $\mathrm{mg}$.), and atropine sulfate (0.3-0.6 mg.), all administered intramuscularly, 30 minutes prior to the procedure unless contraindicated. Subacute bacte- 
rial endocarditis prophylaxis was administered according to recommendations established by the American Heart Association. ${ }^{9}$

The photoresection procedure was performed under either local or general anesthesia. All patients received cardiac monitoring, supplemental oxygen, and intravenous infusion of Ringer's lactate solution by large-bore catheter. Local anesthesia was used when the patient's impaired cardiopulmonary status proscribed general anesthesia, or when he/ she tolerated the initial bronchoscopy well and a brief laser procedure was anticipated. In these patients general anesthesia was utilized when patient discomfort or difficulties with airway control precluded local anesthesia.

Local anesthesia was obtained by the patient's gargling with 50 cc. of 2 percent lidocaine $\mathrm{HCl}$ solution. A cotton-tipped applicator was used to instill 2 percent lidocaine $\mathrm{HCl}$ and a dilution of $1: 10,000$ epinephrine to the nasal passages. Lidocaine $\mathrm{HCl}$ jelly was sniffed into the nostril, and the flexible fiberoptic bronchoscope was introduced. Topical 2 percent lidocaine $\mathrm{HCl}$ was used to anesthetize the vocal cords and tracheobronchial tree in $40 \mathrm{mg}$. boluses, without exceeding a total of $400 \mathrm{mg}$. in any 45-minute period.

Arterial line was inserted in all patients who received general anesthesia. Patients with significant cardiovascular disease had a thermistor-tipped pulmonary artery catheter placed preoperatively. General anesthesia was induced with a nondepolarizing muscle relaxant (pancuronium [1.5-2 mg. administered intravenously] or curare [3-5 mg. administered intravenously]), which was followed by slow intravenous I.V. administration of Pentothal (3-5 mg./kg.) or etomidate $(0.2-0.3 \mathrm{mg}$./ kg.). With loss of eyelash reflex, succinylcholine was given intravenously in the dosage of $1-1.5 \mathrm{mg} . / \mathrm{kg}$. for muscle relaxation to facilitate endotracheal intubation or for introduction of the rigid bronchoscope. A standard polyvinyl chloride (PVC) endotracheal tube of largest possible diameter was used when the procedure was performed with a flexible scope. The cuff of the endotracheal tube was placed just below the vocal cords to allow a safe distance between the tumor site and the inflammable tip of the tube. For management of more proximal tracheal lesions, the portion of the tube distal to the cuff was cut, and the cuff channel was sealed by silicon cement and allowed to set for 24 hours prior to its use. High tracheal lesions were photoresected with a Dumon's rigid bronchoscope, with ventilation being delivered through its anesthesia port. Ventilation ports located on the body of the rigid tube were blocked by metal tape, and the procedure was performed in a closed fashion. In some patients with high tracheal or subglottic lesions, jet ventilation was delivered via an experi- mental triple-lumen, reverse-J-shaped jet ventilation metal cannula approximately $4 \mathrm{~mm}$. in total diameter. The cannula was inserted via the oral route under laryngoscopic guidance, and its distal end was passed beyond the obstruction. Two channels were used for ventilation, while the third measured the airway pressure. Frequency of jet ventilation varied between $70-150$ cycles $/ \mathrm{min} .{ }^{10} \mathrm{In}$ each of these situations, mass spectrometer monitoring was performed (Figs. 1A-C and 2).

Anesthesia was maintained by $0.5-3$ percent enflurane in oxygen or room air. To prevent endobronchial ignition, fraction of inspired oxygen $\left(\mathrm{FIO}_{2}\right)$ was kept below 50 percent during actual firing of the laser energy. ${ }^{11}$ Except when jet ventilation was used, patients were allowed to breathe spontaneously, and ventilation was assisted manually periodically. Topical lidocaine $\mathrm{HCl}$ was used through the channel of the fiberoptic bronchoscope when coughing occurred despite general anesthesia. If this procedure failed to control the cough, a deeper level of general anesthesia was attempted. If hypotension or myocardial depression occurred, nondepolarizing muscle relaxants were used and mechanical ventilation was instituted.

At the end of the procedure, residual neuromuscular blockage was reversed with Prostigmin $(0.08 \mathrm{mg} . / \mathrm{kg}$.) and atropine sulfate $(0.02 \mathrm{mg} . / \mathrm{kg}$.) administered intravenously. Patients were extubated when they were awake and had achieved a negative inspiratory force of more than $25 \mathrm{ml}$. of water and a forced expiratory volume of $10 \mathrm{ml} . / \mathrm{kg}$. of body weight. Oxygen supplementation was continued while the patient was in the postanesthesia recovery unit and as needed thereafter.

\section{Procedure}

The fiberoptic bronchoscope was introduced via the transnasal or transoral route when local anesthesia was administered or jet ventilation cannula was used and through the endotracheal tube when general anesthesia was induced and conventional ventilation was used. With the rigid bronchoscope, the single common channel was used for the laser fiber, a suction catheter, and ventilation. The tumor was localized and photographed before each laser treatment.

Laser light was generated by a 100 -watt Nd-YAG laser (Molectron 8000) and transmitted via a flexible quartz monofilament $(1.9 \mathrm{~mm}$. or $2.2 \mathrm{~mm}$. in diameter). The laser fiber was introduced through the working channel of the fiberoptic bronchoscope or the special port on Dumon's rigid scope. Continuous coaxial airflow through the plastic tubing around the fiber helped to clean the tip and keep the fiber cool. The fiber tip was kept at least $0.5 \mathrm{~cm}$. from the treatment site and $0.5 \mathrm{~cm}$. away from the end of the fiberoptic bronchoscope to prevent ther- 

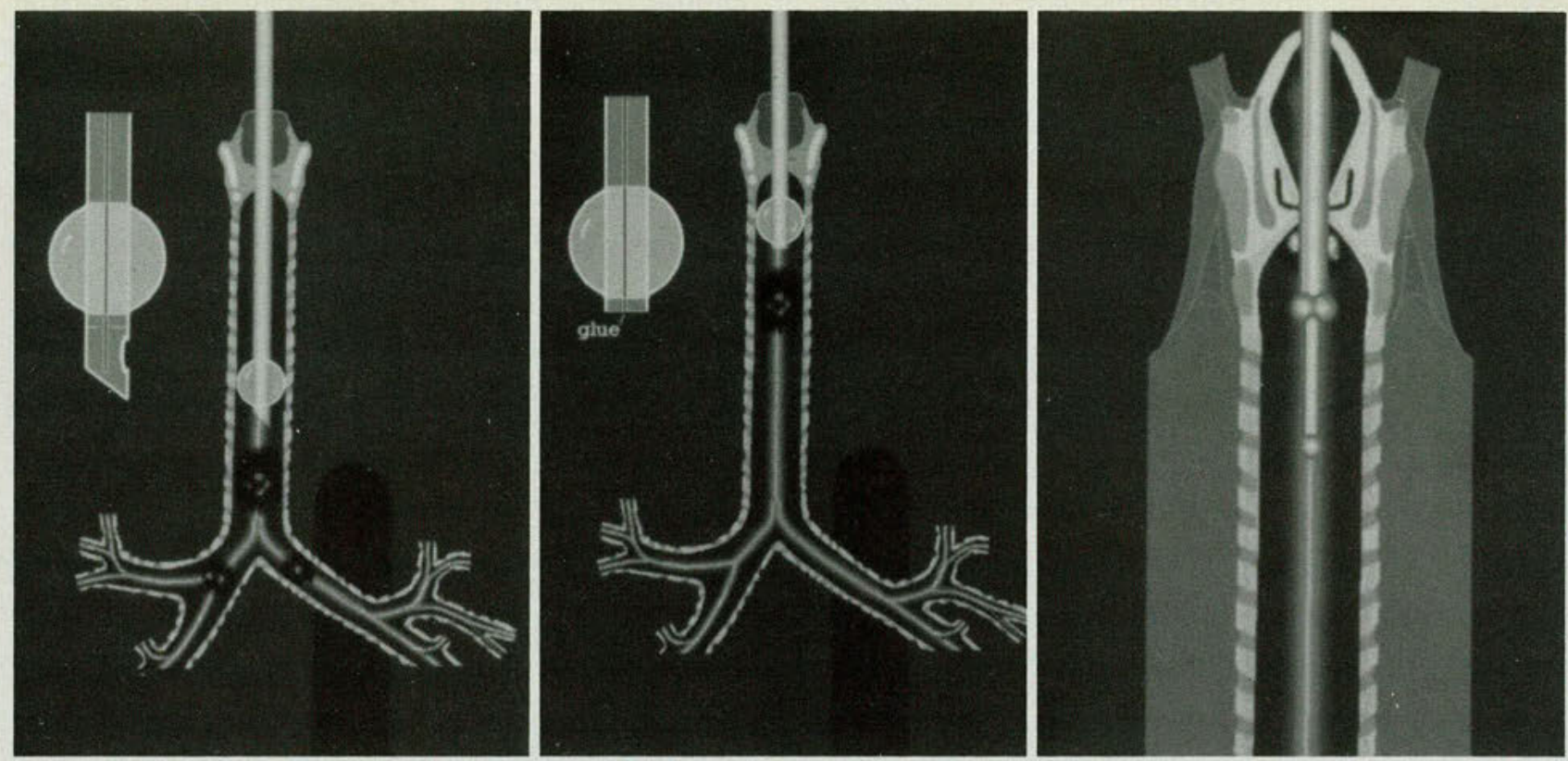

Fig. 1. Schematic diagram of methods of airway maintenance during general anesthesia. $1 \mathrm{~A}$. For lesions involving the lower trachea or major bronchi, the PVC endotracheal tube is shown in place. 1B. For lesions involving midtracheal portion, the portion of the endotracheal tube distal to the cuff is cut off to maintain a safe distance between the lesion and the tip of the tube. The cuff channel is sealed with silicon cement (inset). 1C. For subglottic and higher tracheal lesions, an experimental triple-lumen jet ventilation cannula is positioned to deliver ventilation distal to the lesion.

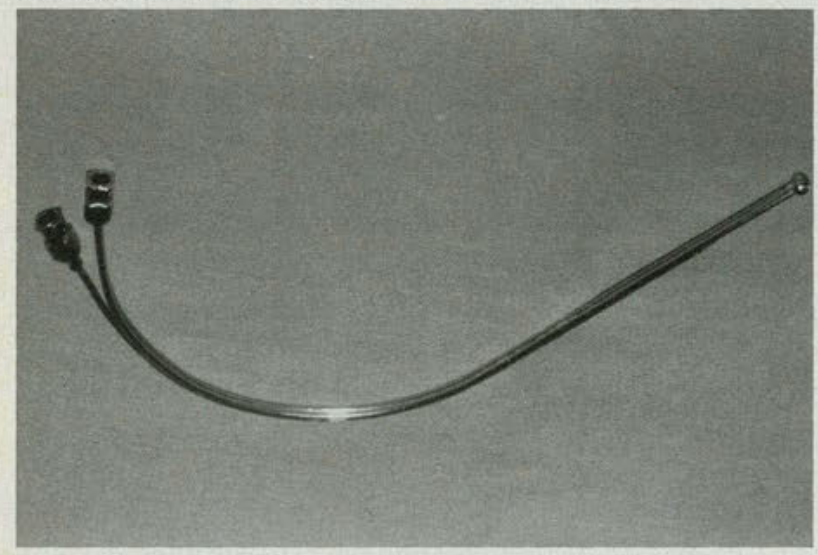

Fig. 2. Experimental triple-lumen jet ventilation cannula.

mal damage to the instrument. Thus, a minimal distance of $1 \mathrm{~cm}$. between the end of the bronchoscope and the treatment site was always maintained and was considered "safety distance." This was not a concern when the rigid scope was used.

Light energy pulses were delivered by pressing the foot pedal of the laser unit. With the beam parallel to the wall of involved airway, laser light was aimed at tumor tissue. The energy dose varied from 40-70 watts for a duration of 0.4-0.5 seconds. Contact sapphire endoprobes of various designs were used in several cases when 70-watt, 0.5 -second settings failed to produce appropriate tissue effects. These contact tips helped to accomplish these desired effects at much lower wattage setting. Because these tips are placed in direct contact with the lesion, laser energy can be delivered from a much shorter safety distance. This advantage also allowed safe treatment of lesions that extended into the lobar and segmental bronchi. ${ }^{12}$ During each procedure, a low setting ( 40 watts at 0.4 seconds) was used initially and increased as necessary to obtain the desired tissue effect. When using contact tips, an initial setting of 5 watts at 0.4 seconds was used and increased as needed. Coagulation (pale discoloration) or carbonization (black discoloration) of the tissue was performed to produce vascular sclerosis and tumor shrinkage. Tumor was then excised in a piecemeal manner using flexible forceps (universal forceps with the rigid scope). This sequence was repeated until all possible exophytic tissue was removed. Both contact and noncontact tips were cleaned periodically with hydrogen peroxide when they were not in use.

The procedure was terminated when total patency of the airway was established or after 5 hours of operating time to avoid operating team fatigue. If optimal results had not been obtained by then, the procedure was repeated after 2 days and the remaining tissue was removed. Multiple biopsies, with single insertion of the forceps, as well as the use of a Dormia basket, snares, and flexible scissors, all helped to remove large pieces of tumor tissue and shorten the duration of the procedure. Frequently, high-wattage and long-duration pulses were fired repeatedly at the same target area to vaporize the tissue. On several occasions, a Fogarty catheter was passed through the fiberoptic bronchoscope to assist in locating and dilating the 
lumen of distal smaller airways. When a rigid bronchoscope was used, the instrument itself was used to shear off the lased tumor from the airway wall. Small or moderate amounts of bleeding from the tumor often was encountered; this was treated successfully in most instances by photocoagulation encircling the bleeding area. The laser fiber was removed from the working channel of the fiberoptic bronchoscope when it was necessary to suction blood. In addition, 2-4 ml. of epinephrine or norepinephrine in a dilution of $1: 10,000$ was instilled endobronchially through the working channel to control bleeding, while closely monitoring the patient's hemodynamic status. The rigid bronchoscope permitted simultaneous use of laser fiber and suction catheter. When necessary, the body of the rigid scope was used directly to tamponade the bleeding site.

\section{Results}

Between September 1983 and 1986, 74 patients (48 men and 26 women) between the ages of 44 and 86 years underwent $88 \mathrm{Nd}$-YAG laser treatments for malignant central airway obstruction. Five patients with large endobronchial lesions required more than one treatment to completely debulk the tumor. During follow up, after establishing complete patency of the involved airways, 4 patients developed endobronchial recurrence requiring repeat laser therapy; 3 of these patients required three treatments and 1 required four treatments.

Chest $\mathrm{x}$-ray findings varied from normal to complete collapse of either lung. Sector CT scans of the mediastinum with contrast enhancement and/or MR imagings were used to delineate vascular anatomy in several patients. MR records no signal from the vessels because of continuous flow of blood, and, therefore, it is more helpful than CT in recognizing the relationship between the involved airway and major vessels. ${ }^{13,14}$

Table 1 lists the major presenting symptoms. The majority of the patients, however, had more than one symptom. Tables 2 and 3 list the lesions by cell type and location, respectively. Lesions were divided into two categories, focal or multifocal, depending on their endobronchial extent. If the tumor process involved a single wall of the airway or extended contiguously to the adjacent wall, the lesion was labeled as focal disease. If the lesion involved more than one wall or the same wall in a noncontiguous fashion, it was labeled multifocal. Focal lesions were further subdivided into two classes. Those extending more than $4 \mathrm{~cm}$. in length were called "focal extensive" disease, and those less than $4 \mathrm{~cm}$. long were called "focal limited" disease. Extensive disease was present in all patients with multifocal disease. Forty-six patients had focal lim- ited disease, 16 had focal extensive disease, and 12 had multifocal disease.

Airway obstruction, which was expressed as a percentage of lumen occupied by the lesion, was measured before and after the procedure. The involved airway was completely occluded in 9 patients (4 right and 5 left main stem bronchus). Flexible forceps or brush were passed by the lesion to determine if the distal lumen was present. When available, sagittal and coronal sections of MR imaging also demonstrated the presence of lumen beyond the obstruction if it existed. In these patients, if the lung or part of the lung was collapsed, efforts were made to determine the duration of the lung collapse by reviewing available past chest radiographs.

Prior to Nd-YAG photoresection, 37 patients received radiation therapy, 4 received chemotherapy, and 9 received both. Twenty-four patients had not received prior chemotherapy or radiation. Patients in the latter group presented with asphyxiation,

\begin{tabular}{|lcc|}
\hline \multicolumn{3}{|c|}{ TABLE 1. MAJOR PRESENTING SYMPTOMS IN 74 PATIENTS. } \\
\hline & \multicolumn{2}{c|}{ Patients } \\
Symptom & No. & Percent \\
\hline Progressive dyspnea & 48 & 65 \\
Hemoptysis & 13 & 18 \\
Intractable cough & 7 & 9 \\
Asphyxiation/stridor & 6 & 8 \\
\hline
\end{tabular}

\begin{tabular}{|lcc|}
\hline \multicolumn{3}{|c|}{ TABLE 2. TYPE OF LUNG CANCER IN 74 PATIENTS. } \\
\hline & \multicolumn{2}{|c|}{ Patients } \\
Type & No. & Percent \\
\hline Primary lung tumors & 57 & 77 \\
Squamous-cell carcinoma & $(37)$ & $(50)$ \\
Large-cell carcinoma & $(10)$ & $(14)$ \\
Adenocarcinoma & $(6)$ & $(8)$ \\
Small-cell carcinoma & $(4)$ & $(5)$ \\
Metastatic lesions & 17 & 23 \\
Renal-cell carcinoma & $(5)$ & $(7)$ \\
Thyroid carcinoma & $(4)$ & $(5)$ \\
Laryngeal carcinoma & $(3)$ & $(4)$ \\
Ciliary body tumor of the eye & $(1)$ & $(1.4)$ \\
Malignant fibrous histiocytoma & $(1)$ & $(1.4)$ \\
Squamous-cell carcinoma of the & $(1)$ & $(1.4)$ \\
cervix & $(1)$ & $(1.4)$ \\
Squamous-cell carcinoma of the & $(1)$ & $(1.4)$ \\
vagina & & \\
Lymphoma & & \\
\hline
\end{tabular}

TABLE 3. LOCATION OF LESION IN 74 PATIENTS.

\begin{tabular}{|lcc|}
\hline & \multicolumn{2}{c|}{ Patients } \\
Location & No. & Percent \\
\hline Trachea (subglottis, 4 patients) & 22 & 30 \\
Right main bronchus & 21 & 28 \\
Left main bronchus & 16 & 22 \\
Intermediate bronchus & 9 & 12 \\
Carina & 4 & 5 \\
Right lower-lobe bronchus & 1 & 1.5 \\
Right upper-lobe bronchus & 1 & 1.5 \\
\hline
\end{tabular}




\begin{tabular}{|c|c|c|c|c|c|}
\hline \multirow[b]{2}{*}{ Results } & \multicolumn{3}{|c|}{ Type of lesion } & \multicolumn{2}{|c|}{ Total } \\
\hline & $\begin{array}{c}\text { Focal } \\
\text { limited }\end{array}$ & $\begin{array}{l}\text { Focal } \\
\text { extensive }\end{array}$ & Multifocal & No. & Percent \\
\hline Excellent & 33 & 7 & 7 & 47 & 63 \\
\hline Good & 13 & 4 & 5 & 22 & 30 \\
\hline Poor & 0 & 5 & 0 & 5 & 7 \\
\hline
\end{tabular}

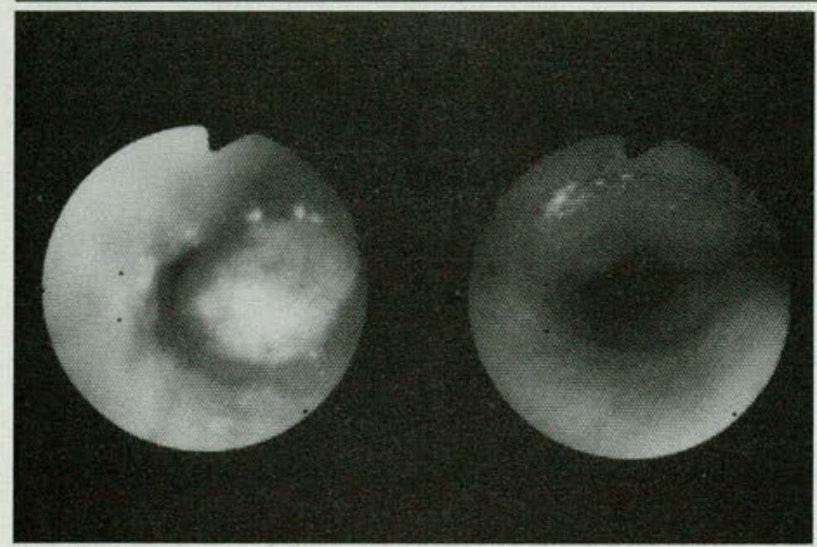

Fig. 3. Squamous-cell carcinoma of the lung producing neartotal obstruction of the trachea before and after laser photoresection in a 44-year-old woman who presented with symptoms of asphyxiation.

progressive hemoptysis, postobstructive pneumonitis, or total collapse of either lung and required immediate treatment. The delayed response to standard radiation therapy or chemotherapy that usually is seen in these non-small-cell carcinoma patients is in sharp contrast to the rapid palliation of photoresection. For this reason, the laser procedure was used as initial therapy.

Seventy-eight procedures were performed using general anesthesia. In 73, the fiberoptic bronchoscope was introduced through a conventional $\mathrm{PVC}$ endotracheal tube. A rigid bronchoscope was used for 2 patients. In 2 patients with subglottic stenosis from metastatic carcinoma of the thyroid and larynx, respectively, ventilation was delivered through a metal tape-wrapped endotracheal tube inserted through the preexisting tracheostomy, and the fiberoptic bronchoscope was introduced transnasally. In the remaining patient with subglottic obstruction from tracheal carcinoma who did not have preexisting tracheostomy, an experimental jet injection cannula was used to bypass the lesion and deliver jet ventilation distal to the obstruction. The fiberoptic bronchoscope with flexible quartz laser fiber was then introduced using the transnasal approach. Ten procedures were performed using local anesthesia; in these cases, the patients were breathing spontaneously and the fiberoptic bronchoscope was introduced transnasally.

All patients were questioned 48 hours after the treatment about subjective improvement. Posteroanterior and lateral chest radiography was repeated within 24 hours, and flow-volume loop study or quantitative ventilation-perfusion lung scan were obtained within a week and compared with preoperative studies to determine the degree of improvement. Table 4 delineates the results for all 74 patients. In patients who presented with symptoms of intractable cough, hemoptysis, or asphyxiation, resolution of symptoms constituted excellent results (Fig. 3). In other patients, results were considered excellent if there was evidence of significant objective improvement, that is, at least 20 percent improvement in the flow-volume loop study or quantitative ventilation perfusion lung scanning (Figs. 4 and 5). Patients who experienced resolution of postobstructive pneumonia or reexpansion of collapsed lobe or lung following the laser therapy also were considered to have excellent results (Fig. 6). If the patient reported marked improvement in his/her symptoms without significant changes in objective parameters, the results were considered good. The result was considered poor if no subjective or objective improvement was present. Good or excellent results were obtained in all 46 patients with focal limited disease, in 11 of 16 patients with focal extensive disease, and in all 12 patients with multifocal disease. The 5 patients with poor results all had focal extensive disease consisting of 100 percent occlusion of the involved airway. Four other patients who had total airway occlusion of less than 2 weeks duration had excellent results.

\section{Complications}

Five of the 74 patients had an adverse effect from the photoresection procedure.

A 51-year-old woman with squamous-cell carcinoma that had metastasized to the left main bronchus and prior anemia had a transfusion reaction during laser photoresection. Sudden hypotension occurred 10 minutes after the transfusion was begun. The patient responded favorably to intravenous fluids, diphenhydramine and methylprednisolone administration.

A 42-year-old man with tracheal metastasis from thyroid carcinoma had laser therapy performed through a Dumon's rigid bronchoscope. Previous thyroid surgery made intubation difficult. After photoresection, this patient had swelling of the vocal cords and epiglottis, which responded to steroid therapy. 
A 75-year-old man with large-cell carcinoma that was metastatic to the trachea had pulmonary hemorrhage immediately following intubation for Nd-YAG photoresection. The endotracheal tube traumatized the lesion, and $500 \mathrm{ml}$. of blood was lost in 5 minutes. Rigid bronchoscopy was required to remove clots and establish ventilation. The $\mathrm{Nd}$ YAG laser was used to cauterize the surface of the lesion and control the bleeding. After 3 stable postoperative days, the patient died of massive hemoptysis and exsanguination. Autopsy revealed invasion of the pulmonary artery by the tumor process.

A 44-year-old woman with squamous-cell carcinoma metastasis to the trachea underwent photoresection three times for palliation of severe dyspnea and stridor. Twenty-four hours after the final treatment, she died from massive hemoptysis and exsanguination. Autopsy revealed invasion of the superior vena cava by the tumor process.

A 57-year-old man with a known history of coronary artery disease and myocardial infarction was prepared for general anesthesia and laser photoresection with nitrates. His squamous-cell carcinoma of the bronchus was treated successfully with the Nd-YAG laser. However, 10 minutes after completion of the procedure, he became hypotensive. Bradycardia and, eventually, cardiopulmonary arrest developed. Efforts at resuscitation were unsuccessful. Autopsy findings revealed recent ischemic myocardial injury, with toal occlusion of the diagonal, proximal, and distal left anterior descending artery, 75 percent stenosis of the left main coronary artery, 95 percent stenosis of the circumflex artery, and 50 percent stenosis of the right coronary artery.

Hypoventilation occurred in 2 patients with subglottic lesions for whom a Dumon's rigid bronchoscope or jet injection cannula with jet ventilation was used. The ventilation side ports as well as the bevelled distal end of the rigid bronchoscope permitted air leaks during treatment of high tracheal and subglottic lesions. These side ports were blocked by metal tape. Gauze packing was used in the oral cavity to minimize the leak from the bevelled distal end of the scope. Hypoventilation during jet ventilation was due to significant upper airway obstruction, which resulted from a combination of preexisting subglottic tumor mass, jet injection cannula, and bronchoscope, as well as from the jet ventilation itself. Hypoventilation did not complicate intraoperative management in either case. Photoresection was stopped when the $\mathrm{pCO}_{2}$ increased to 70 torr. Placing Dumon's rigid scope distal to the lesion temporarily and when jet ventilation cannula was used, suctioning through the channel of the flexible bronchoscope, and occasional removal of the bronchoscope itself helped return the $\mathrm{pCO}_{2}$ to acceptable levels. ${ }^{10}$
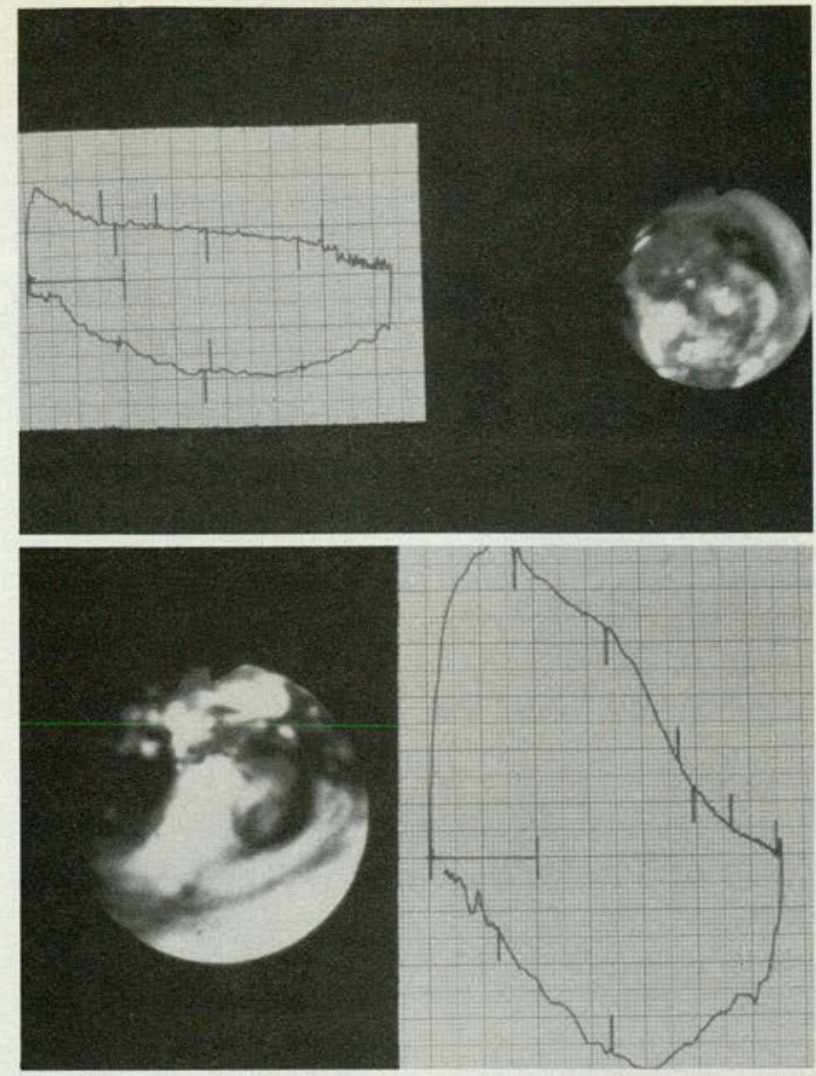

Fig. 4A. Large cell carcinoma producing subtotal occlusion of the trachea just above the carina and corresponding flow volume demonstrating fixed airway obstruction. 4B. Patent tracheal lumen and corresponding normal flow volume loop study following laser photoresection.

In our series, neither complications directly related to the laser beam itself (perforation of a major vessel, pneumothorax, or tracheoesophageal fistula) nor heat-related damage to the endotracheal tube or fiberoptic bronchoscope occurred. However, in a 65-year-old man with complete obstruction of the right main stem bronchus, the metal tip of the laser fiber was lost in the endobronchial tree. Endoscopic retrieval was successful and the procedure was completed using a new laser fiber set. We first experienced this particular complication while attempting to vaporize granulation tissue in a benign tracheal stricture in an 82-yearold woman. ${ }^{15}$ This troublesome problem may become more common than previously thought, especially because separate fiber tips are now available from several manufacturers independent from the manufacturers of quartz fiber. ${ }^{16}$

\section{Conclusions}

This study reaffirms the Nd-YAG laser's safety and efficacy in the management of symptomatic, unresectable, malignant endobronchial lesions. Palliation of symptoms is immediate and in many cases permits definitive therapy to be undertaken. $\mathrm{Pa}$ tients with focal limited disease make excellent 


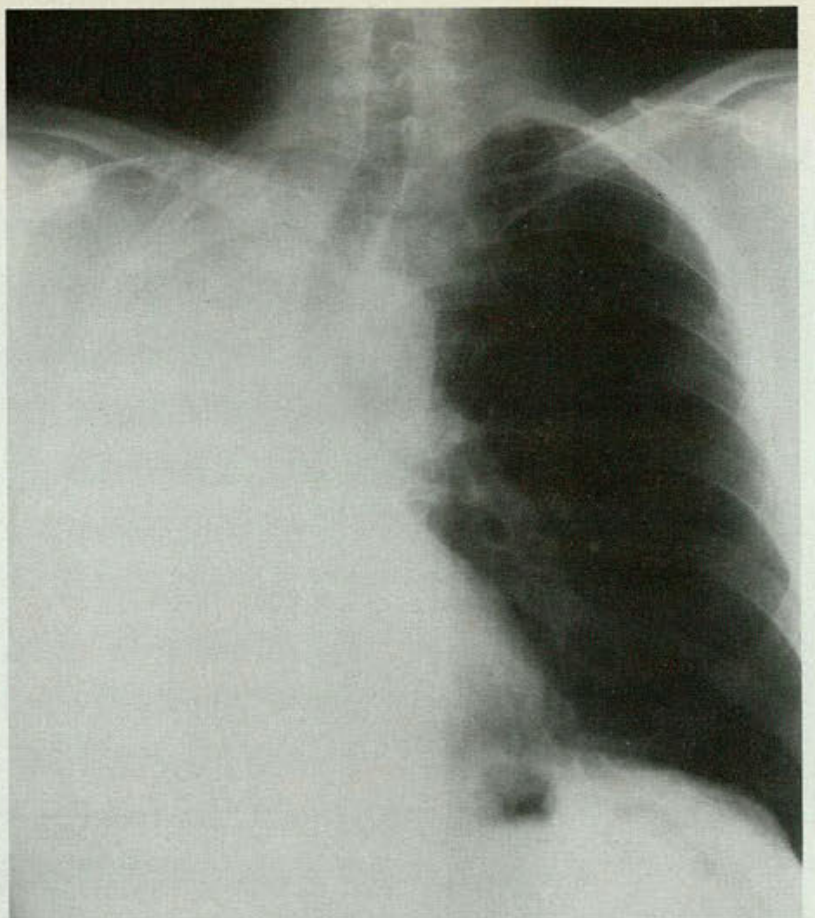

(8) Have a rigid bronchoscope or Carlan's endotracheal tube available as a back up to establish airway in case major endobronchial bleed is encountered.

In conclusion, the Nd-YAG laser transmitted through the fiberoptic bronchoscope is a useful method to relieve endobronchial obstruction from malignant unresectable tumors. The present role of this powerful new technology is in palliation. Its role in prolonging survival of patients with bronchogenic carcinoma has not yet been determined. Its future role as an adjunctive measure to standard therapies, such as chemotherapy and external radiation therapy, as well as to experimental techniques, such as photodynamic therapy and endobronchial irradiation, remains to be studied. ${ }^{17}$

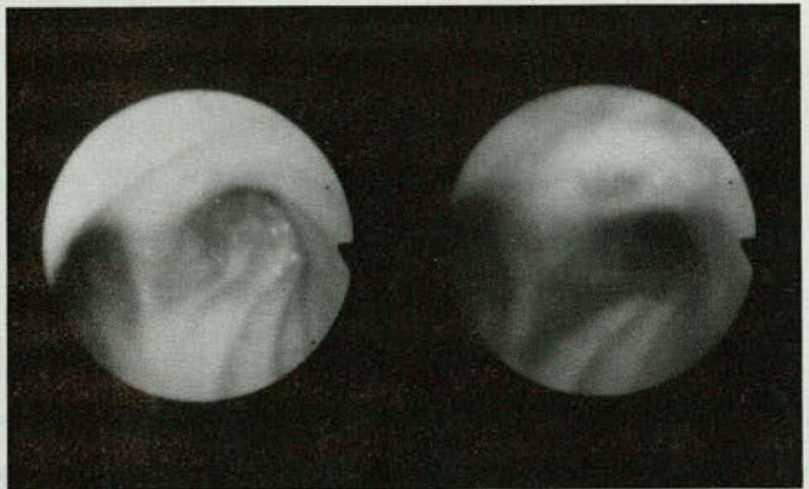

1. Kiefhaber, P., Nath, G., and Moritz, K.: Endoscopical control of massive gastrointestinal hemorrhage by irradiation with a high-power neodymium-YAG laser. Prog Surg 15:140-55, 1977

2. Rutgeerts, P., et al.: Safety and efficacy of neodymium-YAG laser photocoagulation. An experimental study in dogs. GUT 22:38-44, Jan 81 3. Toty, L., et al.: Bronchoscopic management of tracheal lesions using the neodymium-yttrium aluminum garnet laser. Thorax 36:175-8, Mar 81 4. Dumon, J.F., et al.: Treatment of tracheobronchial lesions by laser photoresection. Chest 81:278-84, Mar 82

5. McDougall, J.C., and Cortese, D.A.: Neodymium-YAG laser therapy of malignant airway obstruction. A preliminary report. Mayo Clin Proc 58:35-9, Jan 83

6. Arabian, A., and Spagnolo, V.: Laser therapy in patients with primary lung cancer. Chest 86:519-23, Oct 84

7. Gelb, A.F., and Epstein, J.D.: Laser in treatment of lung cancer. Chest $86: 662-6$, Nov 84

8. Mehta, A.C., et al.: Palliative treatment of malignant airway obstruction by Nd-YAG laser. Cleve Clin Q 52:513-24, Winter 85

9. Kaplan, E.L., et al.: Prevention of bacterial endocarditis. Circulation 56:139A-43A, Jul 77

10. Mehta, A.C., Livingston, D.R., et al.: Ventilatory management during Nd-YAG photoresection of subglottic lesions. Ann Otol Rhinol Laryngol (in press)

11. Casey, K.R., et al.: Intratracheal fire ignited by the Nd-YAG laser during treatment of tracheal stenosis. Chest 84:295-6, Sep 83

12. Mehta, A.C., and Livingston, D.R.: Artificial sapphire contact endoprobe with Nd-YAG laser in the treatment of subglottic stenosis. Chest (in press)

13. Ross, J.S., O'Donovan, P.B., and Borkowski, G.P.: Magnetic resonance imaging of the chest. Initial experience. Cleve Clin Q 52:533-9, Winter 85

14. Mehta, A.C., Livingston, D.R., et al.: Nuclear magnetic resonance vs computerized tomography in preoperative evaluation of laser therapy for airway obstruction (abstract). Chest 89:504S, Jun 86

15. Mehta, A.C., Golish, J.A., and Livingston, D.R.: Loss of fiberoptic laser tip (letter). Chest 88:798, Nov 85

16. Mehta, A.C., and Livingston, D.R.: Loss of fiberoptic laser tip. Further comments. Chest (in press)

17. Eichenhorn, M.S., et al.: Initial combination therapy with YAG laser photoresection and irradiation for inoperable non-small cell carcinoma of the lung. A preliminary report. Chest 89:782-5, Jun 86

Accepted for publication in September, 1986. Updating, as necessary, has been done by the authors.

At the time this paper was written, Dr. Livingston was a Fellow, Department of Pulmonary Disease, Cleveland Clinic Foundation, Cleveland, Ohio. He is now Medical Director of Respiratory Services, Riverside Hospital, Wichita, Kansas. Drs. Mehta and Golish are on the staff, and Dr. Ahmad is Chairman, Department of Pulmonary Disease, and Drs. DeBoer and Tomaszewski are on staff, Department of General Anesthesiology, Cleveland Clinic Foundation.

Dr. Mehta, The Cleveland Clinic Foundation, 9500 Euclid Avenue, Cleveland, Ohio 44106. 
DESCRIPTION: Each milliliter of NASALCROM"s (cromolyn sodium nasal solution, USP) contains $40 \mathrm{mg}$ cromolyn sodium in purified woter With benzalkonium chloride $0.01 \%$ and EDTA (edefate disodium) $0.01 \%$. INDICATIONS: NASALCROM is indicated for the prevention and treatment of the symptoms of allergic minitis. CONTRAINDICATIONS: NASALCROM is contraindicated in those patients who have shown hypersensilivily to any of the ingredients.

PRECAUTIONS: General: Some patients may experience transient nasal stinging and/or sneezing immedictely following instillation of NASALCROM. Except in rare occurrences, these experiences have not caused discontinuation of therapy.

In view of the biliary and renal routes of excrefion for cromolyn sodium, consideration should be given to decreasing the dosoge or discontinuing the odministration of the drug in potients with impoired renal or hepotic tunction. Corcinogenesis, Mutogenesis, and Impairment of Fertility: Long term studies in mice (12 moniths intropentoneal treatment followed by 6 months observation), hamsters ( 12 months intraperitoneal treatment followed by 12 months observation), and ruts (18 months subcutaneous treatment) showed no neoplastic effect of $c r 0$ showed no neoplastic eflect of cro-

No evidence of chromosomal damage or cytotoxicily wos obtained in various mutogenesis studies.

$\mathrm{No}$ evidence of impoired fertility wos shown in loboratory animal reproducfion studies.

Pregnancy: Pregnancy Category B. Reproduction studies with cromolym sodium administered parenterally to pregnant mice, rats, and robbils in doses up to 338 times the human clin ical doses produced no evidence of ical doses produced no evidences of lects (increased resorptions and decreased fetal weight) were noted on at the very high parenteral doses tha produced maternal toxicity There are however no odequate and welcontrolled studies in preanant women. Pecouse animal reproduction studies eccuse an mal ieproduction studies sponse, this thug should be used dusponse, this drug should be used duing pregnancy only il clearly needed. Drug Interaction During Pregnancy. Cromolyn sodium and isoprotereno were studied following subcutaneous injections in pregnant mice. Cromolyn sodium alone in doses of 60 to 540 $\mathrm{mg} / \mathrm{kg}$ ( 38 to 338 times the humon dose) did not cause significant in creases in resorptions or major molto mations isoproter $27 \mathrm{mp}$ limes the of 2.7 ingig (90 imes the human dose) increased bolin resorplions and . lyn sodium (338 times the human dose) to isoproterenol (90 times the human dose) appears to have increased the incidence of both resorptions and maltormations.

Nursing Mothers: It is not known whetherthis drug is excreted in human milk. Becouse many drugs ore ox crint in human mill callon shou creled in human mik, caulion should ministised When NASALCROM is Pediatric Use: Sofely and effectiveness in children below the oge of 6 years have not been established.

ADVERSE REACTIONS: The most frequent odverse reactions occurring in the 430 patients included in the clin cal trials with NASALCROM wore cal tials with tinging (1 in 20) posol burning singing (1 in 20), nasal burning in 25), and nassol imilion ( 1 in 40). Heodoches and bad taste were re ported in about 1 in 50 potients. Epistaxis, postnasal drip, and rash were reported in less than one percent of the patients. One patient in the clinica trials developed anaphylaxis.

Adverse reactions which have $\propto$ curred in the use of other cromolyn sodium formulations for inholution clude angioedema, joint pain in clude angioedema, joint pain and sweling urlicaria, cough, and wheezing. Other reocions reported rarely are serum sickness, penarteritic vosculitis, polymyositis, pericarditis, photodermatitis, extoliative dermatitis, peripheral neuritis, and nephrosis.

NASALCROM* is a registered

trodernark of Fisons plc.

\section{"I LIKE HOW FAST IT WORKS TO STOP MY ALLERGIES, WITHOUT MAKING ME DROWSY:}

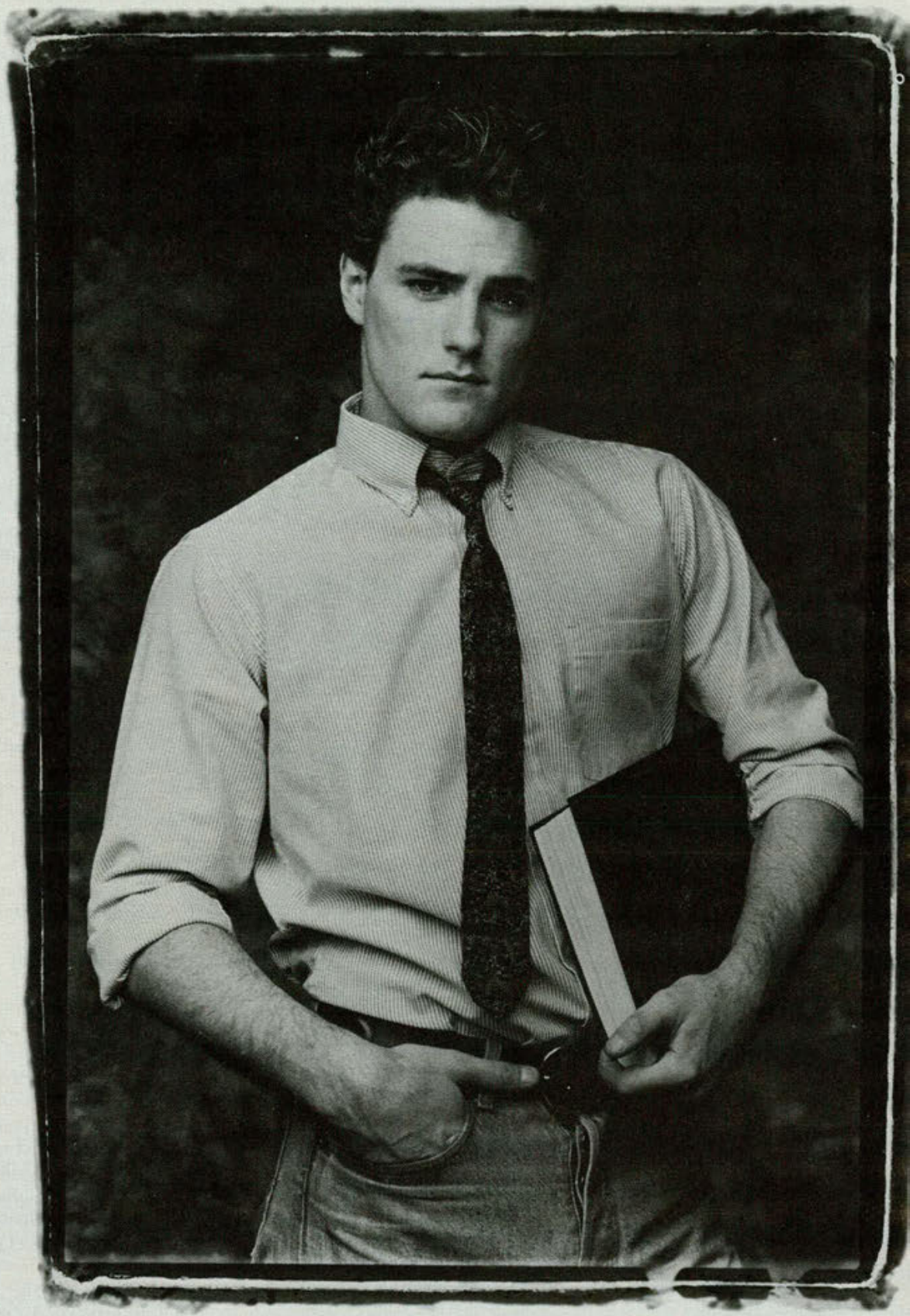

NASALCROM works rapidly-usually within the first few doses-to relieve the congestion, rhinorrhea, and sneezing of seasonal allergic rhinitis. However, for many patients, the side effects of traditional medications can be as troublesome as the allergic symptoms themselves. Unlike these medications, NASALCROM is extremely well-tolerated therapy, virtually uncomplicated by serious side effects, tolerance or contraindications.
NASALCROM (cromolyn sodium/FISONS) without traditional side effects 